\title{
The current state and potential of innovative developments in the service industry
}

\author{
Vasily Zharov* \\ High School of Service Federal State Budgetary Educational Institution of Higher Education \\ RGUTIS, Russia
}

\begin{abstract}
The article analysis the actual state and examine the probable development course of the service industry in the light of the innovative scheme of the economic development. This work reviews the hypothesis that the service industry existing in the modern-day Russian circumstances where the market is at the stage of saturation with both the household and industrial goods becomes that branch of the economy which focuses not only on providing the functioning of the durable goods and satisfying the people's needs for various services but it is also one of the major economic sectors which is capable to adapt to the realities of the modern life while there is the transition to a new technological paradigm. The present work substantiates the necessity to work out the theoretical and methodological grounds and the recommendations for the management in the field of braches of the service industry in the face of development of the innovative digital economy in order to provide the formation of the new technological paradigm considering the current forecasts. The proposed methods for solving the tasks consider the evolutionary innovative processes in the service industry, the concept of serviceology, methods of the management study at various levels of the national economy as well as the researches results in the frame of the digital economy development while creating the new technological paradigm in the Russia Federation.
\end{abstract}

\section{Introduction}

An analysis of the works of a number of researches represents that the service industry becomes a major activity sector in the modern economy both from production and consumptions sides. The increasing role of the services also becomes a substantial part of the people's social life.

The author of this research article points out that it is the consumption of the services that starts to act as the dominant way of satisfying the human needs and the most important factor stimulating production, the main result and sphere of the labour application. In accordance with the author's opinion such activity can indicate the transition from the traditional economic paradigm to the innovative one - the service-digital economy.

This standpoint is substantiated by the research article [1] which contains the data analysis of the dynamics of the economical structure both the developing and developed countries,

\footnotetext{
*Corresponding author: basille@mail.ru
} 
analyzes the architecture of employment and consumption in the society, and assesses the input of the services to the cost of the end product.

As it was said above the service activity either main or associated one is an integral part of the offered product and highly affects the relations between the business entities related to designing, manufacturing and providing various types of services. The activity in the service sector is a chain of the interconnected actions - processes for satisfying the consumers' needs in the corresponding services.

We can remark that the concept in which the service has to be provided in the most convenient, adaptive form for the customer, and sometimes it has to have an individual approach is being of a great importance. For that reason we can say that the service quality is one of the key element of the service itself, the poorly provided service can lead to the degradation not only of the properties of the goods sold along with the service but it also can have a sensible impact on the public image of all the participants involved in the corresponding production-service chain.

Based on the author's opinion it becomes not enough for the manufacturer to just produce a good quality product in the modern market environment because the quality of its sale service and the service support is also important in the battle for the client. Sometimes the high quality manufacturer service has the direct impact on choosing a product that is especially important while comparing similar types of goods by their characteristics. In this case according to many years of the author's observations the decisive difference will be the service and the maintenance starting from the purchasing stage till the end of the product's life cycle. For this reason the service and the maintenance of the goods can provide additional competitive advantages and ensure the income for both the manufacturer and the service company during the entire service life of the product specified by the manufacturer in the documentation which can be formulated in a life cycle contract.

Based on the above material we can say that in the modern market environment at the stage of the market saturation with both the household and industrial goods the service industry of the Russian Federation becomes that branch of the economy which focuses not only on providing the functioning of the durable goods and satisfying the people's needs for various services but it is also one of the major economic sectors which is capable to adapt to the practicalities of the modern life in the transition to a new technological paradigm, the service-digital economy,.

The 2020 COVID-19 pandemic demonstrated the demand for activities providing by the service industry, in particular, educational services, basic and supplementary, consulting services etc. and at this time a new effective connection was observed - the service industry and the digital technologies. During the entire period of lockdowns and self-imposed isolations it could be observed that the digital technologies are most in demand and are best adapted to the service industry. The author of this research work points out that the digital technologies actually establish new, innovative connections between the subjects which often allow achieving a more meaningful result of such interaction against the traditional connections. It is worth saying that it applies to the services that do not require direct personto-person contact. This customer-focused service approach is significant for creating the contractor's competitive advantages when all other conditions being equal. As we can see the service and the maintenance are important for the economic relations between the manufacturers and the consumers. [2, 3]

Since the service is often the system of the person-to-person interaction when considering the actual service activity of a person - the service provider, conditions under which this service is being provided matters much as well as the culture of the service to which the system of the socially accepted norms and labour relations are generally referred to and which belong to a particular state and depend on the internal social organization that has been born in the course of its development. [4] 
High quality level of the customer service is important not only for the service industry but for other economic sectors because it has a positive impact on the collective attitude of the customers both to the organizations providing the service and to the service industry as a whole. [5]

Today the processes in the economics of the most countries of the world are described in the publications as informational, innovative, global, network, knowledge, creative, digital ones etc. They are the consequence of the innovative technologies development in almost all economic sectors. Based on the information of the state economy development level and being focused on the certain innovative technologies this trend can be defined from the position of the predominance of a specific technology. [6, 7]

On the basis of the records $[8,9]$ the service industry is a component of the non-resource sector and its considerable importance is mentioned in the above materials. It should be stressed that in the future the innovations in the non-resource sector of the economy will be crucial in achieving the maturity and sustainability indicators of the national economy.

The author of this work concurs with the opinion of Karpova G.A. and Sushchinskaya M.D. that today these processes are the aspects of the systematic transformation of the economy as a complex of their interrelation together with mediating and stimulating the predominant role of the service industry and its development.

As the researchers remark [1] the economy servicization requires the indicators, the models to define the paths of its development, to define its value for the state economy and also to define the socio-economic suppositions and consequences in the transition to the service-digital economy.

That is why it is necessary to concentrate more on the research works which examine the processes in the economic systems impacting the servicization which is an integral component of the innovative processes of the transition to the service-digital economy described in the research articles as well. $[10,11]$

\section{Materials and methods}

The author of this paper focuses on the necessity to carry out the researches in order to substantiate the theoretical and methodological grounds and develop the recommendations during the establishment of the innovative service-digital approach in the field of the management in the service industry within the frame of the digital economy development which is also highlighted in the document [11].

For that to happen it is necessary to review a set of the missions correlated with the study of the theoretical standpoints of the service industry management concept, the serviceology concept, and the methods applicable to the research of the management at various layers of the national economy. The examination of the innovative development potential of the digital economy should be carried with a view to determine the conceptual approaches to the service industry management.

So the management processes in the service industry become the object of the study and they are understood as the innovations in the service companies allowing to timely adapting to the changes appearing in the service market during the development of the digital economy and appearing of the new technological paradigm. [12]

A combination and interrelation of economical, technical, organizational, managerial fields of the service sector is a subject of this research article that is taking place in the formation of the innovative service-digital management approach of the service sector.

The research methodological basis is formed by using the systematic approach to investigating problems of the capacity assessment, the management factors as well as the research tools for determining the management processes in the branches of the service industry. 
The research methodology presumes the usage of the quantitative and qualitative methods: the panel survey and the expert assessment, the focus groups and the projection methods, the statistical analysis, the economic and social forecasting, the observations, . [10, $13,14]$

The evidence base of the research is represented by the research works related to the problems of the service industry development, the formation of the service including the scientific works of many foreign and domestic scientists: Avanesova G.A., Bagdasaryan T.D., Burmenko T.D., Balaeva O.N., Danilenko N.N., Zvorykina T.I., Karnaukhova V.K., Krakovskaya T.A., Petrova A.N., Platonova N.A., Predvoditeleva M.D., Romanovich Zh. A., Tretyakova T.N., Turenko T.A., Khlebovich D.I., Khoreva I.V., Khristoforova I.V., Lovelock K., Haksever K., Russell R., Merdick R. and other.

The author of this article supposes that the mentioned above research methods are suitable for solving the most vital tasks of the service industry including: the survey of the service sector of the Russian Federation economy in a phase of the transition to the service-digital economy; the examination of the existing provisions and recommendations in the service industry management; the study of the optimization methods and criteria as well as development of the innovative management methods for the branches of the service industry; the determination of the priority tasks of the state regulation of the service industry; the development of the innovative theoretical management model for the branches of the service industry reflecting the informatization impact and the digitalization of the economy and society during the transition to the service-digital economy; the development of the assessment methodology of the service sector companies management effectiveness considering the innovations which allow to timely adapt to the changes arising in the service market in the context of the digital economy development and the formation of the new technological paradigm; the development of the practical guidelines for the management in the branches of the service industry accounting the innovations.

\section{Results and discussion}

After the USSR breakup the state participation in the service industry was mainly reduced to the tax control and suppressing the businessmen informal activities in this sector. [14, 15]

Concurrently, the lack of the control over the quality of the provided services by the state resulted in the fact that the market was filled with the unscrupulous businessmen from whose activities are suffering not only the quality of the providing the goods but the citizens' wellness and this arises the need to define the state participation as a subject of the service sector and as a controller. [5]

Recently in the Russian Federation it can be distinctly seen due to the increase of the opportunities provided by the digital technologies, the services are being carried out by 'the impersonal specialists', 'one-day specialists'. These activities resulted in the unreasonably high prices for the services, the fraudulent schemes are being used, and in fact there is no one to be accused of providing the poor service. It provokes the appearance of the task of the state regulation of the service industry related to the quality control of these services, the control over the qualification and expertise of the service providers and the cost of the provided service subject to taxation. [16]

At the same time the state of the economy as a whole will depend on what will be the policy of the state towards the processes happening in the economic and social spheres. It is impossible to ensure the regeneration of the labour force, increase the labour productivity, improve the educational level and qualification of the labour resources, create the innovative climate to provide the competitive scientific and technological progress, look toward improving the living standards of the citizens, provide appropriate spiritual and cultural life of the society without the involvement of the state instruments. [1, 17] 
As part of this article theme we should mention two forms of the state participation in the service industry- as a manufacturer and as a controller. In this case the digitalization becomes the state's control tool and it facilitates access to the services, provides the transparency of the activities i.e. the self-regulation of this sector of the economy for the business entities and individuals.

The use of the digital technologies in the service industry allows ensuring the transparency of the providers, minimizing or totally eliminating the informal part of this economical sector, increase the tax collection. [10, 18]

The researchers in the research article [1] bring to the attention the statistically confirmed pattern that the processes of the economic servicization are the most typical for the developed economic systems. This is proven by the following indicators of the service industry share in GDP in comparison with GNI per capita determined by the methodology of the World Bank. The percent of the services in GPD for the high-income countries was $74 \%$, for the averageincome countries it was above the level of $57 \%$, for the below average level income countries it was $52 \%$, for the low-income countries it was $48 \%$ in 2004. [10, 19]

As it is stated by the researchers in the work [1] the increase number of employees in the service sector is the most important indicator of the transition to the service-digital economy.

By comparing the employment level by economic sectors for 2000 and 2012 the authors of the article [1] received the general characteristic of this process. According to the comparison within the above time intervals it was shown that $40,4 \%$ of all employed were employed in the agricultural sector and $39,1 \%$ in the service sector in 2000 . As of similar indicators for 2012 there was a rise in the agricultural sector to $31,9 \%$, in the industry - to $23 \%$, the service sector demonstrated the greatest growth to $45 \%$ of the total number of the employed. In comparison with the similar indicators for 2000 and 2012 the developed countries also experience an increase in the number of the employed in the service industry from $67,3 \%$ to $73,9 \%$, a reduction in the agricultural sector from $5,5 \%$ to $3,2 \%$, a reduction in the industrial sector from $27,2 \%$ to $22,5 \%$. [10, 20]

Karpova G.A. and Sushchinskaya M.D. observe the substantive difference in this indicator across the groups of the countries and for specific countries, however, the increase of the employment in the service sector is a general trend which shows the increase in the customers' demand for the services and is one of the indicators of the service sector growth.

As indicated earlier [9] there can be conservative or innovative scenarios of the economic development. With the decrease of the energy resources cost in the external market the innovative development scenario becomes more important which is shown, for instance, by the abrupt changes in those industries where the crisis situations in the economy open up a 'window of opportunity'.

So in 2020 during the pandemic and lockdowns the various services of the distance format became popular around the globe which did not happen earlier, the educational services using the service-digital technologies received the additional opportunities in training methods and the audience coverage. Services for delivery of medicines, food and goods became vital for many categories of the citizens. We can present more examples but they will have one thing in common - the increase in the employment in the service industry which is an important task in the modern economical conditions. The author thinks that these opportunities address and even emphasize the importance of the service industry as one of the most important sources of the employment for the people.

The above examples are applicable not only to a single state but to the majority of the European and Asian countries. This tendency describes the process of the transition to the innovative development scenario for the economics of the developing and developed countries - the transition to the service-digital economy. $[10,11]$

The researchers Evmenov A.D., Bulochnikova I.Y. and Blagova state that the changes in the economy are the cause for appearing of the tasks in the service industry which require 
solving of the methodological problems of the service industry management while reviewing the development innovativeness of this industry.

Joseph Stiglitz also speaks about the methodological problems in the service sector and notes that this is the topical problem especially for the countries where the service sector is the main one. [15]

As it was already brought up the transition to the innovative service-digital economy is characterized by the predominance of the service industry and services in the state economy. The researchers [7] note that the innovations in the service sector are the most in-demand especially taking into consideration the events associated with the 2020 pandemic.

In reliance on the data of the research article [9] it is emphasized that by reason of the growth of the industrial interdependences there will be conditions facilitating the increase of the investments from the foreign businesses. In such situation the share of the service sector funding will be one of the largest.

The authors of the article [7] state that the branches of the extractive sector were the top priority for the state for a long period of time and the service sector was not assumed as a significant part of the economy. This situation has led to the fact that the service sector as an important social tool in the state policy has practically no control which leads to the growth of the informal sector in this industry. The state tried to reduce the informal component of the service sector by allowing the citizens to register themselves as the self-employed persons.

The author of this research article offers an opinion that such measures are not enough to ensure the effective functioning of the Russian service industry and it is essential to progress methodology of the management processes for the service industry in the formation of the innovative environment during the digitalization of the service industry. The authors spoke out on the importance of the assigned problem in the works $[10,11]$.

This aspect is reflected in the document [8] where it is emphasized that it is not possible to create the innovative model suitable for all sectors of the Russian economy because of the fundamental differences in the approaches to the evaluation of the innovative activities. Besides it is required to estimate the impact of the internal and external factors on the study field in order to engage the appropriate resources when solving the assigned tasks.

To estimate the impact of the various indicators on the study field it is proposed to apply the methodology stipulated in the works $[7,10,11]$. The authors propose to use the indicators which describe the state of the environment of the innovation in the service industry in different time periods including the forecast indicators. This methodology allows assessing the significance of each of the chosen indicators in terms of the innovations.

The author of this research work draws attention to the problem of the informal sector of the service industry which can substantially distort the current state of the service sector; thus, it is suggested to apply the comparative analysis of the reporting indicators for the selfemployed citizens in order to have a more accurate picture. [10,11]

The analysis of a number of the works showed that it is rather difficult to evaluate the innovative potential. There are no clear indicators from the perspective of the resource approach. A number of issues related to the assessment of the innovative potential can be settled by involving the knowledge of the OECD experts (Organization for Economic Cooperation and Development). [11]

The author points out that it is a complex task to determine the innovative potential of the service industry and it is necessary to consider a wide range of both the current indicators and the indicators responsible for the prospects for further development of the industry as a whole. 


\section{Conclusions}

The service industry is a diverse one and covers most sectors of the national economy. The mechanism is required to ensure the transparency and safety of the economic activities as well as facilitate the formation of the reasonable and justified pricing policy when setting the prices for the corresponding services.

The fall of the state participation in the service industry has recently led to the adverse effects - the tariff rates for the services in the various sectors are overpriced, there are the service providers who do not have the necessary industry-specific education and the corresponding qualification. Often the services of the low quality are being provided, there are problems with the warranty service of the goods, and the customer's degree of trust towards the service workers is decreasing.

According to the author of this research article this is happening due to the lack of the effective mechanisms for monitoring the carrying out of the activities in the service sector and non-compliance with the legislation of this industry. Here we can also speak about a large volume of the services provided in the "informal sector" and do not fall under taxation which, for sure, is the problem of the state oversight.

Since the respective individuals are the substantial part of the customers in the service industry the processes which are taking place have the impact on each of us, to say the least.

Apart from being the economic system the service industry is the social system as well and can effect on the people's attitude towards the state and this will depend on how the state mechanisms will look like in the field of the management or regulation of the service industry processes. The author of this research work offers an opinion that the consumer should feel protected by the state when interacting with the agents of the service sector which will make these relations more trusting.

We can make reference to the innovative approach as an illustration of such interaction between the state and the consumer - the digitalization in providing the state services on the corresponding innovative digital services. However, the excessive digitalization of the service delivery can become a positive factor for one group of the consumers and negative for another.

The positive result can be demonstrated by an example of providing the state services where the client receives almost the whole range of the services remotely - in the electronic format which has the same legal power as a real 'paper' document.

The negative factor for both the legal entities and the respective individuals can consist in the sensibility to the fraudulent activities and possible damage due to the insufficient protection of the personal data and data constituting commercial or medical secrets for almost all categories of the consumers. This situation signals the necessity of the state participation in the regulation of the service industry.

The clients - the legal entities obtain the services in accordance with the contracts between the business entities and the scope of their interaction is defined by the provisions of the contract which gives a more balanced quality evaluation of the provided services.

In this matter the innovative digital technologies give an additional advantage when managing the service companies remotely, ensure the progress and results of works by means of photo and video recording as well as the transparency of the accounting and other reporting which is especially important when cooperating with the state enterprises. [14, 17, 21]

It should be stated that the service industry for the legal entities can include both the private and state companies. In this case the provision of the services can be carried out in view of the various pricing mechanisms. As regards to the state organizations the price setting for the services can be carried out based on the auctions and tenders and in the case of the commercial companies it can be done on the basis of the commercial expediency. 
This situation can lead to the imbalance of the tariff prices in the service industry and failure to cover the expenses for the providing services. This also shows that there is the need to form the methodology for the innovative environment during the digitalization of the service sector.

The service industry needs the criteria and methods that will ensure the combined functioning of the state control mechanisms and the market self-regulation mechanisms in this sector.

To transit to the service-digital economy in the branches of the service industry and to form the innovative environment methodology are vital issues in terms of the service industry digitalization and the development of the digital economy and the formation of the new technological paradigm.

The service activities cover almost all sectors of the national economy, therefore, the results of this work can be used not only to form the methodology of the innovative environment as part of the service industry digitalization but also in other sectors of the national economy.

\section{References}

1. G.A. Karpova, M.D. Sushchinskaya, The service industry in the modern economy: monograph (2016)

2. V.G. Zharov, N.V. Voronov, S.G. Kuzmishkin, Slavic forum, 2(24), 197 (2019)

3. K.V. Sukhoterina, Business technologies in tourism and hospitality, Service technologies as a tool for increasing the efficiency and quality of the services, 401 (2020)

4. V.G. Zharov, M.V. Runtova, Slavic forum, 1(27), 200 (2020)

5. L.V. Sumzina, A.V. Maksimov, V.G. Zharov, Industrial service, 4(69), 33 (2018)

6. A.B. Tulinov, A.B. Goncharov, A.A. Korneev, Theoretical and practical problems of service, 3(28), 50 (2008)

7. A.D. Evmenov, P.A. Bulochnikov, I.Y. Blagova, Journal of Legal and Economic Studies, 4, 203 (2013)

8. Russia's innovative development strategy to 2020 (approved by the Decree of the Chairman of the Russian Government dated 08.12.2011 No. 2227-p, Rossiyskaya Gazeta, 4864 (2011)

9. The forecast of the long term socio-economic development of the Russian Federation for the period upto 2030, http://old.economy.gov.ru/

10. L. Gokhberg, K. Ditkovskiy, E. Evnevich et al., Indicators of Innovation in the Russian Federation: 2020: Data Book, National Research University Higher School of Economics. - Moscow: HSE (2020)

11. Oslo Manual, Guidelines for Collecting and Interpreting Innovation Data, 3rd Edition Manuel d'Oslo: Principes directeurs pour le recueil et l'interpretation des donnees sur l'innovation, 3e edition OECD/EQ (2005)

12. S.I. Kravchenko, V.M. Dolzhenkova, Scientific works of Donetsk National Technical University. Series: economic, 4, 98 (2008)

13. I. Ansoff, Strategic management (1999)

14. N.V. Blinova, E.V. Gaganova, Human, socio-economic and social sciences, 2(11), 52 (2015)

15. J. Stiglitz, Economic science of modern Russia, 4, 92 (2010)

16. N.M. Komarov, N.V. Ivanov, V.M. Safronov, V.G. Zharov, N.V. Duntsova, K.N. Komarov, Internet journal Naukovedeniye, 1(14), 30 (2013)

17. N.N. Teodorovich, A.I. Mokhov, Evolutionary processes of information technologies. Collection of works based on the materials of the $4^{\text {th }}$ international scientific and technical conference, 97 (2019) 
18. V. G. Zharov, Revista inclusions7, Número Especial (2020), http://revistainclusiones.com/

19. World Development Indicators: Structure of output, http://data.worldbank.org/

20. International labour organization. Global Employment Trends 2014, http://www.ilo.org/

21. A.V. Demenev, V.G. Zharov, R.N. Lopatko, In the collection of works: 2019 International Multi-Conference on Industrial Engineering and Modern Technologies, FarEastCon, 8934034 (2019) 